\title{
Un viaje al país del rey Morvan: cómo adquirir la competencia cultural
}

\author{
A travel to the land of king Morvan: \\ acquiring cultural competence
}

\author{
Lucila María Pérez Fernández \\ Universidad Europea del Atlántico \\ lucila.perez@uneatlantico.es \\ Código Orcid: https://orcid.org/0000-0002-6148-4980 \\ María Araceli Alonso-Campo \\ Universidad Europea del Atlántico \\ araceli.alonso@uneatlantico.es \\ Código Orcid: https://orcid.org/000-0003-0624-222
}

\begin{abstract}
Resumen
El viaje se ha adoptado como una actividad académica en muchas universidades. Sin embargo, su potencial como herramienta didáctica todavía no se ha explotado al máximo. El presente trabajo se centra en el estudio del viaje como herramienta educativa para la adquisición de la competencia cultural en estudiantes universitarios de Traducción e Interpretación. Para ello nos basamos en dos metodologías: el aprendizaje experiencial y el aprendizaje colaborativo. Ofrecemos al alumnado una guía de actividades que deberán completar durante su estancia en el país extranjero incitándolos a reflexionar sobre las mismas y al intercambio de ideas con otros compañeros que estén viviendo una experiencia similar. De este modo, el viaje se erige en una valiosa herramienta que permite aunar las diferentes competencias necesarias para la labor de todo traductor.
\end{abstract}

\section{Palabras clave}

Viaje, cultura, competencia cultural, formación del traductor, estudios en el extranjero, aprendizaje a través de la experiencia.

Forma sugerida de citar: Pérez Fernández, Lucila María y Alonso-Campo, María Araceli (2019). Un viaje al país del rey Morvan: cómo adquirir la competencia cultural. Universitas, 30, pp. 129-150. 


\begin{abstract}
Trips have been adopted as an academic activity by many universities. However, its potential as a teaching tool has not been fully exploited. The present work focuses on the study of travel as an educational tool for the acquisition of cultural competence in Translation and Interpreting students. Our work is based on two main methodologies: experiential learning and collaborative learning. We provide the students with a guide of activities that they must complete during their stay in the foreign country, encouraging them to reflect on them and to exchange ideas with other peers who are living a similar experience abroad. Therefore, the trip becomes a valuable tool that allows us to combine the different competences that every translator must have.
\end{abstract}

\title{
Keywords
}

Travel, culture, cultural competence, translator training, cross-border education, experiential learning.

\section{Introducción}

Es frecuente oír comentarios del tipo "viajar abre la mente", "viajando se aprende", "viajar te permite conocer nueva gente, nuevas lenguas, nuevas culturas" ..., un sinfín de frases donde se evocan los múltiples beneficios de la acción y efecto de "viajar", entendiendo el "viaje" como el "traslado que se hace de una parte a otra por aire, mar o tierra" (DRAE, 2001). Un "viaje" representa una experiencia enriquecedora, por todas las múltiples vías que uno puede atravesar.

Sin irnos a un estudio lexicográfico de la palabra "viaje", no cabe duda de que son diversos los los significados que esta palabra puede adoptar, y de que en todas sus facetas existe una estrecha relación con el ser humano, pues el viaje no deja de ser una travesía que este realiza en la que interactúa con otros seres humanos, facilitando el conocimiento del patrimonio cultural y natural, tanto material como inmaterial, del individuo en sociedad. Es por ello que el viaje se ha conformado como una herramienta didáctica de gran valor en todas las etapas educativas.

Concretamente, en los estudios universitarios, nivel en el que centramos nuestro estudio, el viaje, comienza a configurarse como una actividad obligatoria en muchos grados. En Europa, los programas de movilidad han contribuido a la expansión del viaje como una actividad didáctica para desa- 
rrollar y compartir conocimientos y experiencias en instituciones y organizaciones de distintos países. En algunas universidades europeas, de hecho, el viaje académico ha pasado a formar parte del plan curricular del grado, siendo totalmente obligatorio que el estudiante realice algún viaje para conseguir los créditos necesarios para la obtención del título. No obstante, son escasas las propuestas didácticas específicas para aprovechar al máximo las posibilidades que puede ofrecer el viaje como herramienta didáctica.

El presente trabajo se centra en el estudio del viaje como herramienta educativa para la formación de estudiantes de Traducción e Interpretación que necesitan no solo adquirir la competencia comunicativa en cada una de sus futuras lenguas de trabajo, sino también la propia competencia traductora, en la que se incluye - como explicaremos más adelante - la competencia cultural e intercultural, es decir, la necesidad del traductor de comprender la cultura y los elementos que la conforman.

En primer lugar, presentamos el concepto de cultura, para poder seguidamente centrarnos en el traductor como mediador intercultural, y la visión de cultura desde una perspectiva traductológica. En segundo lugar, nos centramos en el viaje como herramienta facilitadora de la competencia cultural, que ejemplificaremos mediante una secuencia didáctica.

\section{El cultivo de la cultura}

La palabra "cultura" proviene del latín cultus que significa etimológicamente "cultivo". Se trata de un término que ha experimentado una gran evolución a lo largo de la historia.

En el siglo XIII el latín relacionaba esta palabra con el cultivo de la tierra. Siglos más tarde, en torno al siglo XVI, empezó a adquirir un sentido más figurado y se empezó a hablar de cultivar la mente, las facultades intelectuales.

En la Ilustración (siglo XVIII), surge un concepto más elitista del término con la dicotomía entre gente "con cultura" y "sin cultura", de forma que se establecía una división entre personas "cultas" e "incultas". Así, la cultura se asociaba principalmente con la "alta cultura" entendida esta como la perfección espiritual de la música clásica o las artes plásticas consagradas.

En el siglo XIX Tylor (1871 en Kahn, 1975) acuñó una de las definiciones más clásicas y aceptadas del término cultura: 
La cultura o civilización, en sentido etnográfico amplio, es ese todo complejo que incluye el conocimiento, las creencias, el arte, la moral, el derecho, las costumbres y cualesquiera otros hábitos y capacidades adquiridos por el hombre en cuanto miembro de una sociedad (p. 29).

En 1930, Franz Boas da un giro a esta definición al concebir la cultura como un fenómeno plural que incluye:

Todas las manifestaciones de los hábitos sociales de una comunidad, las reacciones del individuo en la medida en que se ven afectadas por las costumbres del grupo en que vive, y los productos de las actividades humanas en la medida en que se ven determinadas por dichas costumbres (Boas, 1930 en Kahn, 1975, p. 14).

Por lo tanto, esta definición pone de manifiesto que cada sociedad tiene una cultura propia.

En el ámbito de la didáctica de las lenguas extranjeras también se han ido produciendo cambios en torno al concepto de cultura. González (2012) explica que en los enfoques estructurales la cultura se concebía como algo secundario, si bien se contemplaba en los planes de estudio, su papel en los manuales se limitaba a reflejar estereotipos de la sociedad de la lengua meta, desconectados de los objetivos de la lengua y generalmente descontextualizados.

El enfoque comunicativo supuso un cambio de perspectiva en la forma de concebir la cultura en la didáctica de lenguas. Adaskoy et al. (1990) establecen cuatro clases de cultura que se deben abordar en la enseñanza de lenguas: estética (logros artísticos), sociológica (costumbres); semántica (significados de la lengua) y pragmática (cultura de la interacción y de las situaciones). Para lograr efectuar un intercambio comunicativo exitoso es necesario que los interlocutores conozcan el valor que se otorga a cada uno de esos aspectos en cada una de las culturas, pues por el desconocimiento de esas pautas sociales surgen los choques y malentendidos culturales (González, 2012).

García (2004) define muy bien todas las variables que se incluyen dentro del concepto de cultura desde el punto de vista del aprendizaje de lenguas extranjeras:

El concepto de cultura se define a partir de diversas variables tales como: las características medio ambientales, climáticas y atmosféricas, el entorno paisajístico; las condiciones demográficas; los parámetros de conducta asociados con ceremonias, las festividades, las prácticas rituales y las creen- 
cias mágico religiosas; las convenciones sociales (puntualidad, regalos, vestidos, los tabúes relativos al comportamientos en conversaciones, etc.); el nivel de desarrollo social y tecnológico de las diversas sociedades; la familia; las relaciones entre los sexos; las estructuras sociales y la relación entre sus miembros; los contactos corporales (saludos, despedidas, ofrecimientos, etc.); los hábitos diarios (comidas, transportes, compras, aficiones y ocio, horas y práctica de trabajos); la lengua o lenguas y sus literaturas; las tradiciones; las salud y los cuidados corporales; la educación; los gestos y las expresiones faciales; la religión; la vivienda y el hogar; los mitos, los ritos, los cuentos, las creencias, las supersticiones y el humor. Todos estos parámetros crean y delimitan entornos culturales específicos (p. 18).

Por lo tanto, el aprendizaje de una lengua extranjera implica necesariamente la inclusión del componente cultural de manera que se permita al estudiante desarrollar estrategias interculturales que le permitan llevar a cabo una comunicación exitosa. García $(2004$, p. 4) señala que para ello el hablante necesita "partir de lo conocido, de lo adquirido y de lo aprendido por su experiencia personal". Es precisamente esta última idea la que nos lleva a plantear nuestra propuesta didáctica desde el enfoque del aprendizaje experiencial, tal y como veremos más adelante.

\section{El traductor como mediador intercultural}

La relación entre cultura y traducción es innegable. Aunque no conocemos el momento exacto del nacimiento de la profesión, sabemos que su figura fue fundamental como vía de comunicación entre los distintos pueblos. Así, la transmisión de los conocimientos científicos y filosóficos del mundo griego y árabe fue posible principalmente gracias a la labor de traducción llevada a cabo en esa época (Carrera, 2013).

Son varios los traductólogos que han reflexionado sobre el concepto de cultura en relación con la traducción. Uno de los primeros fue Nida (1945), quien a partir de su experiencia como traductor bíblico, propuso el concepto de "equivalencia dinámica" que persigue que el mensaje provoque en el receptor meta el mismo efecto que en el receptor original, por lo que para ello será necesario adaptar los elementos culturales que no tengan el mismo significado o sean desconocidos por el receptor del texto de llegada. 
Para Nord (1997) cuando traducimos comparamos culturas, es decir, actuamos como mediadores entre la cultura origen y la cultura meta, idea que Hatim y Mason (1995) amplían cuando indican lo siguiente:

Los traductores median entre culturas (lo cual incluye ideologías, los sistemas morales y las estructuras sociopolíticas) con el objetivo de vencer las dificultades que atraviesan el camino que lleva a la transferencia de significado. Lo que tiene valor como signo en una comunidad cultural puede estar desprovisto de significación en otra, y el traductor se encuentra inmejorablemente situado para identificar la disparidad y tratar de resolverla (Hatim \& Mason, 1995, p. 282).

Witte (1992) señala que la comunicación entre culturas empezó a estudiarse de manera sistemática en los años 70 con la creación del área de investigación lntercultural Communication Studies. En el ámbito de la didáctica de la traducción son varios los autores (Nord, 1988; Bell, 1991; Kiraly, 1995; Hurtado, 1996) que han desarrollado modelos de "competencia traductora", definida por Kelly (2002, p. 9) como el "conjunto de capacidades, destrezas, conocimientos e incluso actitudes que reúnen los traductores profesionales y que intervienen en la traducción como actividad experta". Estos modelos suelen presentarse divididos en subcompetencias. Una de ellas es la "competencia cultural" (también denominada "competencia intercultural" por algunos autores). Wilss (1976) fue uno de los primeros en incluirla en su modelo de competencia traductora. Para él se trata una "supercompetencia" y la define como "la habilidad para transferir mensajes entre sistemas lingüísticos y textuales". Más adelante Nord (1991) y Neubert (2000) incluyeron también la competencia cultural como uno de los parámetros necesarios dentro de la competencia traductora.

Kelly (2002, p. 14) en su modelo de competencia traductora también incluye la competencia cultural como una de las subcompetencias e indica que "comprende no sólo conocimientos enciclopédicos con respecto a los países donde se hablan las lenguas correspondientes, sino también sobre los valores, mitos, percepciones, creencias y comportamientos y sus representaciones textuales". También el grupo PACTE (2003) hace referencia a la competencia cultural, pero como parte de la subcompetencia extralingüística. Por lo tanto, comprobamos que son numerosos los expertos que entienden la figura del traductor como un mediador no solo lingüístico, sino también cultural capaz de identificar y anticipar posibles problemas en la comunicación 
entre hablantes de culturas diferentes derivados de las diferentes formas en las que ven el mundo.

Para Taft (1981) resulta fundamental que todo mediador cultural posea conocimientos avanzados de las culturas con las que trabaja y dentro de esos conocimientos destaca los siguientes:

- Conocimientos sobre la sociedad.Aquí se incluyen aspectos como la historia y los personajes relevantes en ella, las tradiciones o las costumbres.

- Habilidades comunicativas, como el uso correcto de las convenciones lingüísticas y del lenguaje corporal.

- Habilidades técnicas adaptadas a la situación: uso de las tecnologías, conocimiento del entorno, etc.

- Habilidades sociales: conocimiento de las normas que rigen las relaciones sociales.

Así pues, el conjunto de todos estas habilidades hacen que el traductor "no se erija tan sólo como un mero transmisor de palabras, sino como un verdadero eslabón" (Ponce, 2007), capaz de facilitar el entendimiento entre dos culturas diferentes, pues aquello que puede tener valor y considerarse un signo cultural inequívoco dentro de una determinada comunidad cultural, en otra puede no ser así y es al traductor a quien le corresponde identificar esa disparidad y encontrar la forma de abordarla (Hatim \& Mason, 1990).

Teniendo en cuenta estas características, coincidimos con Gregorio (2012) en que no es posible enmarcar la concepción de cultura durante el proceso de formación de traductores en una asignatura concreta, sino que se trata de un proceso que se nutre también de aquellas experiencias que los estudiantes puedan vivir fuera del aula. Así, el viaje constituye una herramienta de gran utilidad, puesto que permite que los futuros traductores conozcan in situ los diversos factores que intervienen en toda interacción comunicativa, ya sean formales (cortesía, turnos de palabra, lenguaje no verbal, etc.), o significativos (valores sociales, factores psicológicos o emotivos, etc.) (Raga, 2007).

\section{El viaje como herramienta para la adquisición de la competencia cultural}

La firma de convenios de movilidad entre universidades ha crecido notablemente en los últimos años y en consecuencia el número de estudian- 
tes que hacen estancias académicas en otros países ha aumentado también (Martínez et al., 2013).

De acuerdo con Castillo (2017), los orígenes de la movilidad académica estudiantil se remontan a finales del siglo XVI, cuando diversos jóvenes aristócratas ingleses eran enviados a hacer el gran-tour una vez terminados sus estudios para complementar su formación. Solían ser viajes largos, de entre 3 y 5 años, en los que recorrían diferentes países europeos y cuyo principal objetivo era que esos jóvenes obtuviesen la formación necesaria para poder hacerse cargo de su país en el futuro. Soriano (2017) sitúa el primer ejemplo de movilidad directamente relacionada con la formación de traductores en Bagdad en el siglo IX, en la denominada House of Wisdom y en España en el siglo XII, en la Escuela de Traductores de Toledo.

Como decíamos, actualmente los estudiantes universitarios pueden beneficiarse de múltiples programas académicos de movilidad internacional. Soriano (2017) destaca los siguientes:

En primer lugar, el programa Erasmus, uno de los más conocidos y en el que más alumnos participan. De hecho su nombre ha pasado a usarse de manera cotidiana. Así, este término ha traspasado el ámbito académico y lo usamos tanto para referirnos a los participantes como al programa (Soriano, 2017). Asimismo tenemos el programa Socrates, Lingua (más enfocado al aprendizaje de lenguas), Leonardo (enfocado a la formación profesional), Grundvig (para adultos u otros itinerarios educativos) y Minerva (Programa sobre educación abierta y a distancia). De igual manera, las Universidades suelen contar con convenios bilaterales establecidos con determinadas universidades que no se encuentran en Europa o que simplemente no forman parte del programa Erasmus.

En relación con la traducción todavía son escasos los trabajos que relacionan su didáctica con los programas de movilidad. Uno de los pioneros abordando este tema fue Pym (1992), quien llevó a cabo un estudio sobre la experiencia de estudiantes de intercambio en tres universidades. Más adelante, Mayoral y Kelly (1997) analizaron las consecuencias de la presencia de estudiantes de intercambio en las clases de traducción de la Universidad de Granada. Uno de los estudios más recientes es el de Soriano (2017), quien se centra en la evaluación de un programa de movilidad en la formación de los futuros traductores tanto desde el punto de vista de los estudiantes como de los profesores y gestores del intercambio. 
De todas estas investigaciones podemos extrapolar ciertas conclusiones comunes en lo que respecta a los beneficios de los programas de movilidad para la adquisición de la competencia cultural del traductor:

- Favorecen la mejora del nivel lingüístico y cultural del traductor, pues le permiten acercarse a un sistema universitario nuevo con metodologías diferentes.

- Permiten abordar mejor la relación con otros entornos y sus peculiaridades (comidas, horarios, etc.).

- Permiten que los estudiantes comprendan la carga cultural que hay detrás de ciertas actitudes no compartidas en sus propias culturas.

No obstante, cabe destacar que aunque esta subcompetencia sea la que a priori es más visible y detectable por el propio alumnado, las demás subcompetencias (instrumental, profesional, estratégica, psicofisiológica) también se ven beneficiadas.

Tal y como hemos visto, la movilidad estudiantil contribuye al desarrollo de la competencia traductora de los estudiantes del grado de Traducción e Interpretación. Como ya se ha señalado, es habitual que las universidades españolas ofrezcan este tipo de programas a su alumnado, que pueden optar a ellos de manera voluntaria. Sin embargo, teniendo en cuenta los múltiples beneficios que supone para un futuro traductor un viaje académico de este tipo nos gustaría analizar cuántas universidades españolas establecen la movilidad académica como obligatoria dentro de sus planes de estudio. Para ello hemos extraído del Ministerio de Educación, Cultura y Deporte, el listado de universidades que cuentan con el programa de grado en Traducción e Interpretación y hemos revisado los planes de estudio. Descubrimos que de un total de veintitrés universidades que imparten el grado de Traducción e Interpretación tan solo una establece como requisito obligatorio que los estudiantes se vayan fuera durante al menos un semestre, si bien todas las demás ofrecen la posibilidad voluntaria a través de los ya mencionados programas de movilidad.

A la hora de analizar los planes de estudio hemos prestado también especial atención a las asignaturas ofertadas, con el fin de averiguar cómo logran las universidades suplir las salidas al extranjero de algunos de sus estudiantes. Así, vimos que una gran parte de las universidades analizadas ofertan asignaturas en las que se abordan aspectos culturales. Algunos ejemplos son: 
- Contrastes lingüísticos y culturales de la lengua B.

- Traducción y cultura: Historia, género y ética de la traducción.

- Lengua y Cultura B/C.

- Cultura aplicada a la Traducción.

- Fuentes culturales para la traducción.

- Cultura y civilización europeas.

- Traducción de variedades lingüísticas.

- Traducción y cultura.

- Pragmática Intercultural.

- Relaciones Internacionales.

- Oriente y Occidente: culturas en contacto.

- Cultura y Civilización Anglosajonas, Germánicas, francófonas.

- Traducción, literatura y cultura.

- Idioma C y su cultura.

- Historia y cultura de los países de habla B.

- Pensamiento contemporáneo e interculturalidad.

Como se puede observar, todas ellas incluyen el término "cultura" o "interculturalidad" en su título y en algunas de ellas (Lengua y cultura, por ejemplo) se pretende recalcar que no solo se presta atención a la parte lingüística, sino a la parte cultural.

No obstante, coincidimos con Soriano (2010) en que los intercambios de movilidad constituyen un pilar indispensable en la formación de los futuros traductores intérpretes, puesto que contribuyen positivamente al desarrollo de la competencia traductora.

\section{El aprendizaje experiencial y el aprendizaje colaborativo}

Aunque nos centramos en la subcompetencia cultural, nos interesa también que los estudiantes adquieran todas las demás subcompetencias que conforman la competencia traductora, por eso consideramos que la metodología que mejor encaja en nuestra propuesta es el aprendizaje experiencial, ${ }^{1}$ pues en ella el alumno se sitúa en el centro del aprendizaje y es posible combinar varios factores como la experiencia, la autonomía o la cognición. Se

1 Para más información sobre esta metodología, véase Pardo et al. (2015). 
trata, por lo tanto, de una metodología activa en la que el estudiante experimenta un desarrollo tanto a nivel profesional como personal.

Kolb (1984) fue uno de los primeros autores que se interesaron por esta metodología, también conocida como learning by doing. Para él se trata de un proceso en el que el conocimiento se crea a partir de la experiencia y lo señala como fundamental para el desarrollo del estudiante. Dewey (1995, p. 125) coincide con esta visión e indica que los beneficios de este tipo de aprendizaje residen en que "hacer se convierte en ensayar, en un experimento con el mundo para averiguar cómo es; y el sufrir se convierte en instrucción, en un descubrimiento de la conexión de las cosas".

En los modelos de enseñanza tradicionales el profesor es quien se sitúa en el centro del proceso de aprendizaje y el alumno desempeña un papel pasivo en el que obtiene conocimiento de su instructor y después lo aplica. El aprendizaje experiencial se basa justamente en lo contrario, pues sostiene que para adquirir conocimiento lo eficaz será trasladar el papel protagonista al alumnado. Esto se debe a que cuando los estudiantes tienen que enfrentarse a situaciones reales acaban consolidando "un conocimiento significativo, contextualizado, trasferible y funcional y se fomenta su capacidad de aplicar lo aprendido" (Romero, 2010, p. 90). Para que esto ocurra es necesario que los estudiantes lleven la iniciativa e interactúen con el medio.

Aunque la mayoría de las propuestas basadas en este enfoque se basan generalmente en experiencias relacionadas con las ciencias exactas, coincidimos con Paleari (2017) en que es posible beneficiarse de él para el estudio de las humanidades y en concreto de la Traducción e Interpretación. Se pretende, por tanto, promover el desarrollo de la capacidad de aprender a aprender, una habilidad fundamental, pues será una destreza que todo profesional de la traducción necesitará a lo largo de toda su vida. Pero tal y como señala Romero (2010), no es posible asegurar ese aprendizaje simplemente con la experiencia, sino que esta debe estar ligada a un proceso de reflexión personal. Por este motivo, pensamos que es necesario proporcionar al alumnado una serie de pautas que les ayuden en esa fase de reflexión.

Asimismo, queremos también incidir en el aprendizaje colaborativo (Barkley et al., 2007; Delgado, 2016), pues como señala Landone (2004, p. 2) este hace hincapié en "las relaciones interpersonales y la experiencia colectiva como fuentes de crecimiento personal, social y cognitivo de los estudiantes". Así pues, no solo contribuye a mejorar las competencias linguiístico-comunicativas, sino que también fomenta el desarrollo de otras 
competencias (sociales, cognitivas, etc.). A este respecto, nos interesa sobre todo que los estudiantes tengan acceso a las experiencias de los compañeros que se encuentran en otros países. Para ello, estableceremos un contacto permanente a través de una plataforma virtual, tal y como explicaremos en el siguiente apartado.

\section{Un recorrido por el país del rey Morvan}

La presente propuesta didáctica está dirigida a estudiantes del grado de Traducción e Interpretación y se ha diseñado con el objetivo de que estos aprovechen los programas de estudios en el extranjero como un aprendizaje activo, práctico y consciente, de manera que adquieran la competencia cultural que todo traductor necesita para desempeñar su labor traductológica con eficacia. A su vez, se adopta una metodología basada en el aprendizaje experiencial y colaborativo para poder, a partir de las vivencias experimentadas en el viaje y su propia reflexión sobre las mismas, y la interacción e intercambio de ideas con otros compañeros, desarollar las competencias transversales de manera natural.

Para la configuración de la secuencia didáctica nos hemos inspirado en las necesidades de los estudiantes del Grado en Traducción e Interpretación de la Universidad Europea del Atlántico, y en los programas de movilidad Erasmus. Por un lado, nuestra intención era que el alumno aprendiera de manera individual a partir de su propio viaje; por otro lado, queríamos que también aprendiera de la experiencia de otros compañeros que hubieran tenido que descubrir otro destino.

Como toda secuencia didáctica, la propuesta está conformada por una serie de actividades que podemos dividir en tres grupos: actividades de apertura, actividades de desarrollo y actividades de cierre. Si situamos las actividades en el espacio-tiempo, la actividad de apertura la realizaría el estudiante antes del viaje, en su universidad de origen, la actividad de desarrollo durante el viaje, en el lugar de destino, y la actividad de cierre, después del viaje, de nuevo en la universidad de origen.

Al tratarse de alumnos de Traducción e Interpretación, usaremos la Torre de Babel como metáfora del viaje que cada alumno ha de realizar a una región con una lengua y cultura diferentes, de manera que cada estudiante ha de construir su propia torre según el destino que le haya sido asignado. 
A continuación, desglosaremos las diferentes actividades agrupadas según los diferentes pisos que conforman la torre, y que a su vez, constan de una o varias tareas. Cada piso de la torre se refiere a uno de los ámbitos temáticos del patrimonio cultural y natural de la zona que se visita. Cada temática se ilustra mediante un color diferente y para recorrer cada piso, el estudiante ha de realizar varias tareas. La consecución de todas las tareas de un piso, le permite al alumno pasar al siguiente piso e ir así construyendo la torre. Para motivar al alumno, una vez completadas todas las tareas de un piso, los estudiantes obtendrán una miniatura de la torre del color del piso. Los estudiantes tendrán que obtener tantas miniaturas como pisos tenga la torre para obtener su Torre de Babel.

Asimismo, y con el fin de que los alumnos estén durante todo el proceso de la secuencia didáctica en contacto y puedan colaborar e intercambiar experiencias e impresiones, completarán un cuaderno de viaje, donde plasmarán los resultados obtenidos en cada una de las tareas y podrán ver el proceso de aprendizaje de sus compañeros también. Para la entrega de las tareas, haremos servir un Weblog, ya que es una herramienta 2.0 que permite combinar el trabajo individual con el trabajo colaborativo - véase Larrondo y Tejedor (2010) para el uso del Weblog como herramienta para la elaboración de cuadernos de viaje.

Para ejemplificar la secuencia, hemos seleccionado uno de los destinos a los cuales suelen viajar los estudiantes: Francia, y concretamente, la zona de la Bretaña, por ser una región conocida por su gran riqueza histórica, cultural y natural. En el título de nuestra propuesta hacemos referencia al país del rey Morvan, pues consideramos que se trata de un personaje muy representativo de dicha región. En el año 818 se negó a someter a Bretaña al imperio de Occidente y desde entonces se le bautizó con el sobrenombre de LezBreizh (literalmente "apoyo de Bretaña"). Sin embargo, su reinado fue muy corto, pues ese mismo año murió en una batalla. Coadic (2017) señala que las consecuencias de su derrota fueron principalmente religiosas. Por ejemplo, los monjes irlandeses y escoceses establecidos en el bosque de Brocelianda se vieron obligados a cambiar sus reglas cristiano-celtas y adoptar las benedictinas y Bretaña tuvo que abandonar el catolicismo.

A continuación, presentamos las diferentes actividades y tareas planificadas. 


\section{Construyendo la Torre de Babel Un viaje al país del rey Morvan}

El viaje que va a emprender el estudiante comienza en el mismo momento en el que se le asigna un destino. Como todo viajero uno ha de prepararse, indagar sobre el lugar que va a visitar, y realizar una planificación. Es por ello que concebimos un primer bloque de tareas de apertura que permita al estudiante comenzar el camino con las herramientas necesarias para que viva una experiencia formativa. Seguidamente, se presenta la actividad de desarrollo que en sí conforme el núcleo principal de la secuencia didáctica. Por último, quedaría la actividad de cierre, pues es necesario que el estudiante muestre sus hallazgos, comparta las piedras que ha podido encontrar en el camino, y reflexione sobre su propio proceso de aprendizaje. A continuación, presentamos cada una de las actividades que, a su vez, están conformadas por diversas tareas.

\section{Actividades de apertura}

Estas primeras tareas se realizarán en el aula antes del inicio del viaje.

Tarea 1: Explicación de la secuencia didáctica.

Objetivo: Mostrar y explicar toda la secuencia didáctica, y las diferentes actividades que el alumno ha de realizar, así como los instrumentos necesarios para la entrega de las diferentes tareas.

Tarea 2: Situación en el espacio

Objetivo: Ubicar geográficamente el área objeto de estudio

Enunciado: Elabora un mapa de la región de la Bretaña con sus diferentes departamentos para poder utilizarlo a lo largo del viaje.

\section{Actividades de desarrollo}

Como ya indicamos, con las diferentes actividades que conforman esta parte los estudiantes podrán ir profundizando en los diferentes ámbitos temáticos que conforman el patrimonio cultural de la zona a la que han viajado. Cada piso se corresponde con uno de esos ámbitos y se representa mediante un color. La finalización de las tareas que conforman un piso permitirá al alumnado pasar al siguiente y de este modo construir la torre. A continuación, presentamos el ejemplo visual de las áreas que conforman nuestra Torre de Babel. 


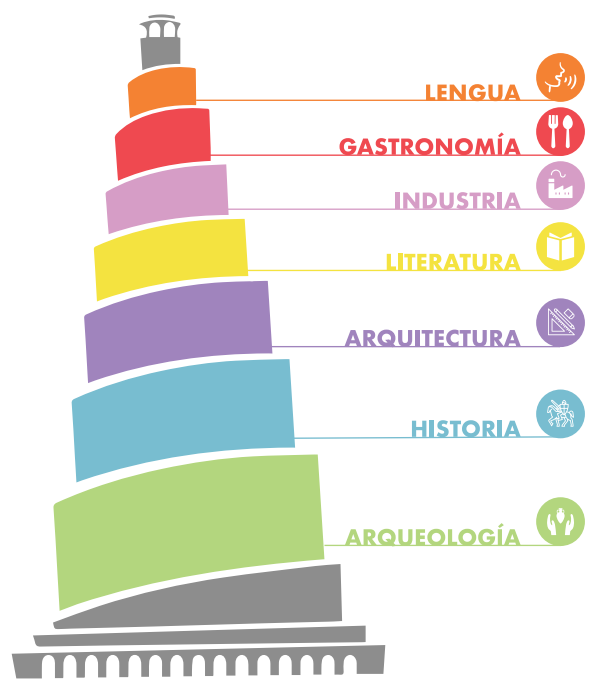

ARQueOLOGÍA

Tarea 1: Los megalitos

Objetivo: Conocer los yacimientos megalíticos que se encuentran repartidos por todo el territorio bretón.

Enunciado: Bretaña es una de las regiones más importantes de la cultura prehistórica. En ella se encuentran una gran cantidad de yacimientos megalíticos. Averigua en qué zonas se hallan y los tipos de construcciones que se pueden ver en cada localización. Después elabora una ruta de viaje destinada a turistas que quieran visitar la región.

Tarea 2: Los vestigios celtas

Objetivo: Conocer el origen.

Enunciado: En el año 500 a.C., los celtas llegaron con su civilización a la península bretona. Averigua los nombres de los diferentes pueblos y en qué zonas se asentaron. Acude al Museo de Bretaña en Rennes y descubre el legado celta que allí permanece custodiado. Por último, descubre en qué lugar concreto los romanos lograron vencer al último pueblo celta. Elabora un texto expositivo sobre el legado celta en el que se muestre lo aprendido en el Museo de Bretaña.

Pregunta final del bloque: ¿Qué nombre recibía Bretaña cuando estaba habitada por los celtas? 
HISTORIA

Tarea 1: La duquesa de Bretaña

Objetivo: Conocer el papel que desempeñó la duquesa Ana de Bretaña en el desarrollo de la Bretaña como región.

Enunciado: La duquesa de Bretaña nació en el castillo de Nantes. Viaja hasta esta ciudad y averigua todo lo que puedas sobre la vida y reinado de Ana de Bretaña. Visita el museo Thomas-Dobrée y descubre qué pertenencia de la duquesa alberga. ¿Con cuántos reyes se casó?

Tarea 2: Los piratas

Objetivo: Conocer la historia de Saint Maló como ciudad corsaria.

Enunciado: Te proponemos ahora un viaje a Saint-Maló, la ciudad natal de Jacques Cartier (descubridor de Canadá en 1534). En esta ciudad se halla el Hotel de Asfeld, una joya arquitectónica que esconde un secreto sobre su historia. ¿Podrías indicar cuál?

Tarea 3: La compañía de las Indias

Objetivo: Conocer la relevancia de la Compañía Francesa de las Indias Orientales en la historia del comercio de Francia.

Enunciado: En la ciudad Port-Louis se encuentra el Museo de la Compañía de las Indias, un museo único en Francia en el cual podrás contemplar las diferentes mercancías que se transportaban al otro lado del mundo. Elabora un álbum de fotos con los objetos más relevantes.

Tarea 4: La base de submarinos de Kéroman

Objetivo: Conocer una de las etapas de la historia de Francia marcada por la ocupación alemana.

Enunciado: La ocupación del ejército alemán de Lorient en 1940 se hace patente a través de una enorme construcción edificada por los nazis. Descubre de qué se trata y elabora un informe en el que hagas referencia a los momentos clave de ese periodo.

Pregunta final del bloque: ¿Cómo contribuyó la historia a que se forjara una fuerte identidad bretona?

\section{ARQuitectura}

Tarea 1: Las casas bretonas.

Objetivo: Conocer las características singulares de las casas bretonas.

Enunciado: La ciudad de Poul-Fetan se encuentra en el departamento de Morbihan. En ella se encuentran los Pen-ty. Averigua qué son y el material del que están hechos. 
Tarea 2: Los recintos parroquiales.

Objetivo: Conocer uno de los elementos más característicos de la arquitectura religiosa de Bretaña.

Enunciado: Bretaña está cubierta de recintos parroquiales, conjuntos arquitectónicos únicos fruto del fervor religioso de la región. Descubre en qué villas se encuentran y qué representan los calvarios, una de sus partes fundamentales. Elabora una guía de viaje en la que señales el lugar dónde se hallan, qué tienen en común todas las zonas en las que podemos encontrar un recinto parroquial, una breve descripción del estilo y el conjunto arquitectónico en sí y aporta al menos una fotografía.

Tarea 3: Las villas medievales.

Objetivo: Conocer las características arquitectónicas de las villas medievales. Enunciado: Bretaña conserva villas medievales capaces de transportarnos al pasado. Averigua cuáles son y documenta fotográficamente todas tus visitas a estas.

Tarea 4: Las fortalezas y castillos.

Objetivo: Entender la influencia de la historia en las construcciones arquitectónicas de la región.

Enunciado: Bretaña fue objeto de deseo de diversos rivales por lo que para defenderse tuvo que construir murallas, fortalezas y castillos. Elabora una ruta por las principales en la que indiques el periodo en el que se enmarcan y las principales características arquitectónicas.

Pregunta final del bloque: ¿Qué relación guarda uno de esos castillos con la película Los vikingos?

\section{LITERATURA}

Tarea 1: Las leyendas celtas.

Objetivo: Conocer la rica tradición de la literatura popular de Bretaña a través de sus relatos populares.

Enunciado: Los cuentos y leyendas forman parte del alma bretón. Indaga acerca de las diferentes leyendas y prepara un audio a modo de cuentacuentos en el que narres la historia.

Tarea 2: La Materia de Bretaña.

Objetivo: Entender la relevancia de la Materia de Bretaña en la literatura francesa.

Enunciado: La Materia de Bretaña hace referencia a una serie de textos escritos durante la Edad Media en torno a la corte del rey Arturo y los caballeros 
de la Mesa Redonda. Muchos de los episodios descritos en las novelas transcurren en un bosque ubicado en Bretaña. Averigua cuál es, visítalo y localiza los puntos emblemáticos que contiene.

Pregunta final del bloque: ¿Qué son los Étonnants Voyageurs y con qué ciudad se asocian?

\section{INDUSTRIA}

Tarea 1: La industria textil.

Objetivo: Conocer la materia prima de la industria textil, y los motivos de su desarrollo.

Enunciado: Encuentra un profesional de la industria textil y realízale una entrevista sobre el desarrollo de esta industria en Bretaña.

Tarea 2: La industria conservera.

Objetivo: Conocer el desarrollo de la industria conservera.

Enunciado: La pesca es una actividad clave en Bretaña. Visita una fábrica de conservas y averigua cómo se ha desarrollado la industria conservera de manera tan fructífera.

Pregunta final del bloque: ¿Qué objeto se comercializó con enorme éxito a partir del desarrollo de la industria textil?

\section{GASTRONOMÍA}

Tarea 1: La gastronomía bretona.

Objetivo: Conocer la gastronomía local.

Enunciado: Elige un plato típico de la zona en la que resides, busca la receta y grábate en la elaboración del proceso del plato.

Pregunta final del bloque: ¿Qué tiene de especial la galette de Bretaña?

\section{LENGUA}

Tarea 1: El bretón.

Objetivo: Conocer la diversidad lingüística de la región de Bretaña.

Enunciado: El idioma bretón es el único representante de las lenguas célticas en Francia. Se trata de una lengua minoritaria pero con presencia en la región. Infórmate a través de compañeros de clase del estatus de dicha lengua y entrevista a algún hablante de bretón que pueda contarte de primera mano la situación actual del idioma bretón.

Tarea 2: El galó.

Objetivo: Conocer la diversidad lingüística de la región de Bretaña. 
Enunciado: El galó es otra de las lenguas propias de Bretaña. Se trata de una lengua minoritaria con poca literatura escrita, pero es posible encontrar diversas referencias a este idioma, como por ejemplo en carteles dispuestos por diferentes ciudades. Recopila los ejemplos que encuentres.

Pregunta final del bloque: ¿En cuántos dialectos se divide el bretón y cuáles son?

\section{Actividades de cierre}

Estas últimas tareas se realizarán en el aula una vez finalizado el viaje. Las dos tareas están pensadas para que el alumno interactúe con los compañeros que han experimento un viaje académico, y compartan sus experiencias.

Tarea 1: Presentación oral del Cuaderno de viaje.

Objetivo: Mostrar al resto de compañeros su experiencia de viaje.

Enunciado: Elabora una exposición oral donde presentes tu cuaderno de viaje, prestando especial atención a tu propio proceso de aprendizaje de la competencia cultural e intercultural.

Tarea 2: Enseñando a enseñar.

Objetivo: Enseñar al resto de compañeros lo aprendido.

Enunciado: Elabora un Trivial para que el resto de compañeros puedan aprender de tu viaje.

Esta segunda tarea se configura como una tarea colaborativa, pues cada alumno que ha ido a un destino diferente tendrá que configurar su propio trivial, de manera que se vaya creando un Trivial global para aprender el patrimonio cultural y natural de los diferentes destinos.

\section{Consideraciones finales}

En el presente artículo hemos ofrecido una propuesta didáctica centrada en el viaje como herramienta educativa para la adquisición de la competencia cultural. En este sentido, volviendo al significado originario de la palabra "viaje", el alumno se enfrentará a un peregrinaje en busca de los diferentes vestigios que le permitirán ir descrubiendo los elementos culturales, tanto tangibles como intangibles.

En nuestra secuencia ofrecemos una serie de tareas divididas en bloques temáticos. Cabe aquí destacar que el número de bloques puede variar en función del lugar de destino y de las preferencias del docente. Asimismo es nece- 
sario señalar que en nuestra propuesta nos centramos solamente en el desglose de la secuencia y, puesto que la enmarcamos en el contexto de los programas de movilidad, no abordamos el aspecto de la evaluación. No obstante, dentro de la configuración de los programas españoles sería posible incluir este aspecto si otorgamos a la secuencia el estatus de actividad extracurricular, de manera que los estudiantes pudiesen optar a conseguir créditos adicionales.

Así pues, mediante nuestra propuesta didáctica pretendemos explotar al máximo la experiencia de movilidad del alumnado incidiendo no solo en la parte lingüística, sino también en el aspecto cultural de modo que los estudiantes realicen una inmersión total en la cultura del país que los acoje y descubran de primera mano los elementos que configuran dicha cultura.

\section{Bibliografía}

Adaskoy, K., Britten, D. \& Fahsi, B. (1990). Design decisions on the Cultural content of a secondary English course for Morocco. ELT Journal, 44(1), pp. 3-10.

Barkley, E. F., Cross, D. P. \& Manzano, P. (2007). Técnicas de aprendizaje colaborativo: Manual para el profesorado universitario. Madrid: Ministerio de Educación y Ciencia.

Carrera, J. (2013). El papel del traductor como mediador intercultural. Recuperado de https://goo.gl/UCtakZ

Castillo, I. (2017). El valor de la movilidad universitaria internacional como modalidad del turismo idiomático. España y Alemania (Tesis doctoral). Universidad de Córdoba, Córdoba.

Coadic, X. (2017). El Grial: Mitos y simbolismos de la Búsqueda. Las grandes figuras: Arturo, los caballeros de la Mesa Redonda...Barcelona: De Vecchi.

Bell, R. T. (1991). Translation and translating. Londres: Longman.

Delgado, K. (2016). Aprendizaje colaborativo. Teoría y práctica. Bogotá: Magisterio.

Dewey, J. (1995). Democracia y educación: una introducción a la filosofía de la educación. Madrid: Morata.

García, P. (2004). La cultura: ¿universo compartido? La didáctica intercultural en la enseñanza de idiomas. RedELE: Revista electrónica de Didáctica ELE, pp. 1-6.

González, C. (2012). Caracterización del concepto cultura en la didáctica de las lenguas. Cartaphilus. Revista de investigación y crítica estética, 10,pp. 84-108.

Gregorio, A. (2012). La competencia cultural e intercultural en Traducción: estado de la cuestión. Íkala, revista de lenguaje y cultura, 17(2), 129-144. 
Hatim, B. \& Mason, I. (1995). Teoría de la traducción: una aproximación al discurso. Barcelona: Ariel.

Hurtado Albir, A. (1996). La cuestión del método traductor. Método, estrategia y técnica de traducción. Sendebar, 7, 39-57.

Kahn, J. S. (1975). El concepto de cultura: Textos Fundamentales (escritos de Tylor (1871), Kroeber (1917), Malinowski (1931), White (1959), y Goodenough (1971)). Barcelona: Anagrama.

Kelly, D. (2002). Un modelo de competencia traductora: bases para el diseño curricular. Puentes, 1, 9-20.

Kiraly, D. C. (1995). Pathways to translation. Pedagogy and process. Kent: The Kent State University Press.

Kolb, D. A. (1984). Experiential Learning: Experience as the Source of Learning Development. New Yersey: Prentice-Hall.

Landone, E. (2004). El aprendizaje cooperativo del ELE: propuestas para integrar las funciones de la lengua y las destrezas colaborativas. Red ELE. Revista Electrónica de Didáctica ELE, 1-23.

Larrondo, A. \& Tejedor, S. (2010). Cuadernos de viaje 2.0: Análisis de las oportunidades del Weblog para relato de viajes. Tercer milenio: Revista de comunicaciones, periodismo y ciencias sociales, 19, 1-25.

Martínez, F.; Pereira, X. \& Pawlowska, E. (2013). El turismo académico en Galicia: Otra forma de contribución de las Universidades a las economías locales. Cuadernos de Turismo, 32, 229-242.

Mayoral, R. \& Kelly, D. (1997). Implications of multilingualism in the European Union: Translator training in Spain. En Labrum, M. (Ed.), The Changing Scene in World Languages (pp. 19-34). Amsterdam: John Benjamins.

Nord, C. (1988). Textanalyse und Übersetzen. Theoretische Grundlagen, Methode und didaktische Anwendung einer übersetzungsrelevanten Textanalyse. Heidelberg: J. Gross Verlag.

Nord, C. (1991). Text analysis in translation theory, methodology, and didactic application of a model for translation-oriented text analysis. Amsterdam: Rodopi.

Nord, C. (1997). Translating as a Purposeful Activity: Functionalist Approaches Explained. Manchester: St. Jerome Publishing.

PACTE (2003). Building a translation competence model. En F. Alves (Ed.), Triangulating translation: Perspectives in process oriented research (pp. 4366). Amsterdam: John Benjamins. 
Paleari, V. (2017). Hacia un entorno más auténtico en el aprendizaje del español como lengua extranjera. El enfoque experiencial. Lingue e Linguaggi, 23, pp. 151-167. Recuperado de https://goo.gl/KZ9xsY

Pardo, R., Irureta-Goyena, P. \& González, T. (2015). Educación experiencial como Innovación Educativa. Madrid: Plaza Valdés.

Ponce, N. (2007). El apasionante mundo del traductor como eslabón invisible entre lenguas y culturas. Revista electrónica de estudios filológicos, 13. Recuperado de https://goo.gl/mWJvNh

Pym, A. (1992). Translation error analysis and the interface with language teaching.

En C. Dollerup y A. Loddegaard (Eds.), Teaching translation and interpreting: Training, talent and experience (pp. 279-288). Amsterdam/ Filadelfia: John Benjamins.

Raga, F. (2007). Conversaciones interculturales: algo más que palabras. En Grupo CRIT, Culturas cara a cara: Relatos y actividades para la comunicación intercultural (pp. 25-42). Madrid: Edinumen.

Romero, M. (2010). El aprendizaje experiencial y las nuevas demandas formativas. Revista de antropoligía experimental, 10(8), pp. 89-102. Recuperado de https://goo.gl/XoJBEA

Soriano, I. (2010). La movilidad estudiantil y sus implicaciones en la formación de futuros traductores. Estudio de caso, Puentes, 9, 19-28. Recuperado de https://goo.gl/D7be5F

Soriano, I. (2017). Evaluación de un programa de movilidad en la formación de traductores: expectativas, experiencias y grado de satisfacción de los participantes, profesores y gestores del intercambio MGLU-UGR-ULPGC (Tesis doctoral). Universidad de Granada, Granada.

Taft, R. (1981). The role and personality of the Mediator. En Bochner, S. (Ed.), The Mediating Person: Bridges between Cultures. Cambridge: Schenkman.

Witte, H. (1992). El traductor como mediador cultural. Fundamentos teóricos para la enseñanza de la Lengua y Cultura en los estudios de Traducción. El Guiniguada, N Extra 3, 407-414. Recuperado de https://goo.gl/PfJwU1

Fecha de recepción: 2018/11/20; Fecha de aceptación: 2019/02/14; Fecha de publicación: 2019/03/0I 